\title{
Radiotherapy of oligometastatic prostate cancer: a systematic review
}

\author{
Paul Rogowski ${ }^{1 *}$ (D, Mack Roach $\mathrm{II}^{2}$, Nina-Sophie Schmidt-Hegemann ${ }^{1}$, Christian Trapp ${ }^{1}$, \\ Rieke von Bestenbostel ${ }^{1}$, Run Shi ${ }^{1}$, Alexander Buchner ${ }^{3}$, Christian Stief ${ }^{3}$, Claus Belka ${ }^{1,4}$ and Minglun Li ${ }^{1}$
}

\begin{abstract}
Background: Due to improved imaging sensitivity, the term "oligometastatic" prostate cancer disease is diagnosed more often, leading to an increasing interest in metastasis-directed therapy (MDT). There are two types of radiation based MDT applied when treating oligometastatic disease: (1) stereotactic body radiation therapy (SBRT) generally used for bone metastases; or (2) SBRT for isolated nodal oligometastases combined with prophylactic elective nodal radiotherapy. This review aims to summarize current evidence data, which may shed light on the optimal management of this heterogeneous group of patients.

Methods: A systematic review of the Medline database through PubMed was performed according to PRISMA guidelines. All relevant studies published up to November 2020 were identified and screened. Fifty-six titles were included. Besides outcome parameters, different prognostic and predictive factors were assessed, including site of metastases, time between primary treatment and MDT, use of systemic therapies, hormone sensitivity, as well as pattern of recurrence.
\end{abstract}

Findings: Evidence consists largely of retrospective case series and no consistent precise definition of oligometastasis exists, however, most investigators seem to acknowledge the need to distinguish between patients presenting with what is frequently called "synchronous" versus "metachronous" oligometastatic disease. Available data on radiotherapy as MDT demonstrate high local control rates and a small but relevant proportion of patients without progressive disease after 2 years. This holds true for both hormone sensitive and castration resistant prostate cancer diseases. The use of ${ }^{68} \mathrm{Ga}$-PSMA PET/CT for staging increased dramatically. Radiation doses and field sizes varied considerably among the studies. The search for relevant prognostic and predictive factors is ongoing.

Conclusions: To our best knowledge this review on oligometastatic prostate cancer included the largest number of original articles. It demonstrates the therapeutic potential and challenges of MDT for oligometastatic prostate cancer. Prospective studies are under way and will provide further high-level evidence.

Keywords: Oligometastatic prostate cancer, Metastasis-directed therapy, Radiotherapy, SBRT, ENRT

\section{Background}

Prostate cancer (PC) is the second most common cancer in men worldwide [1]. After primary treatment with radical prostatectomy or radiation therapy $(\mathrm{RT})$, a relevant

*Correspondence: paul.rogowski@med.uni-muenchen.de

1 Department of Radiation Oncology, University Hospital, LMU Munich, Marchioninistr. 15, 81377 Munich, Germany

Full list of author information is available at the end of the article proportion of patients develop metastases. Immediate or delayed androgen deprivation therapy (ADT), chemotherapy, chemohormonal therapy and palliative radiotherapy have traditionally been the mainstay of the management of metastatic prostate cancer (MPC) [2].

However, sensitive PSA detection and improved imaging are increasingly leading to the diagnosis of "oligometastatic disease", which in turn has raised new questions concerning the value of metastasis-directed

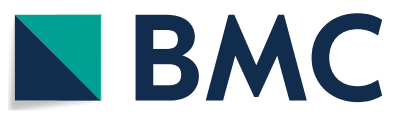

(c) The Author(s) 2021. Open Access This article is licensed under a Creative Commons Attribution 4.0 International License, which permits use, sharing, adaptation, distribution and reproduction in any medium or format, as long as you give appropriate credit to the original author(s) and the source, provide a link to the Creative Commons licence, and indicate if changes were made. The images or other third party material in this article are included in the article's Creative Commons licence, unless indicated otherwise in a credit line to the material. If material is not included in the article's Creative Commons licence and your intended use is not permitted by statutory regulation or exceeds the permitted use, you will need to obtain permission directly from the copyright holder. To view a copy of this licence, visit http://creativecommons.org/licenses/by/4.0/. The Creative Commons Public Domain Dedication waiver (http://creativeco mmons.org/publicdomain/zero/1.0/) applies to the data made available in this article, unless otherwise stated in a credit line to the data. 
therapy (MDT) on progression free survival (PFS) and overall survival (OS). The definition of oligometastatic disease is inconsistent and varies from as few as one but up to between three and five metastases. Malignant cells in this state are supposed to have a limited metastatic capacity, accompanied with less aggressive behavior [3]. Accumulating evidence suggests that local MDT could defer disease progression, delay the need of systemic therapies and spare their toxicities. However, in some cases, clinical oligometastasis is only the tip of the iceberg for a subclinical polymetastatic disease. Proper patient selection, as well as the definitions use and relevant endpoints may be critically important to optimal approach oligometastatic disease [4].

Radiotherapy and in particular stereotactic body radiation therapy (SBRT), also sometimes called stereotactic ablative radiotherapy (SABR), presents a logical option for MDT and has been used in many retrospective case series. Figure 1 shows the growing number of publications on oligometastatic PC in the last 7 years.

Timing of the diagnosis of oligometastatic disease seems to be widely held to be important. For example, $68 \%$ of expert participants in the advanced prostate cancer consensus conference (APCCC) considered it important to distinguish between patients presenting with what is frequently called "synchronous" versus "metachronous" (appeared later in the course of the disease) oligometastatic disease. Further, despite the lack of high-level evidence, $64 \%$ of APCCC members voted for an ablative MDT in metachronous oligometastatic PC [5]. This systematic review provides an overview of the evidence to date for MDT in oligometastatic PC.

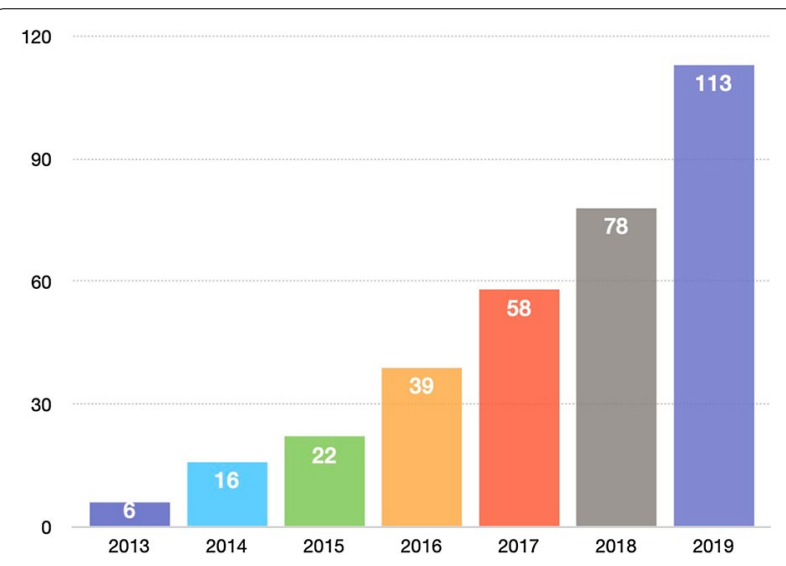

Fig. 1 Publications on oligometastatic prostate cancer

\section{Methods}

A systematic review of the Medline database trough PubMed was performed in October 2019 and updated in November 2020 according to PRISMA (Preferred Reporting Items for Systematic Reviews and Metaanalysis) guidelines. Search terms used were: "prostate cancer", "radiotherapy", "oligometastatic" and "metastasis-directed" or combinations of these. Further inclusion criteria were (a) original article; (b) article in English; (c) accessibility to the full article; (d) cohort consists of oligometastatic PC patients only; (e) MDT was radiotherapy. Additional references were identified from the bibliographies of candidate articles. To minimize publication and reporting bias, case series that comprised fewer than five cases were excluded. Moreover, studies in which not all metastases were treated or just a palliative radiotherapy was conducted were excluded as well. Two studies without sufficient clinical survival data were also excluded. The study selection process is shown in Fig. 2.

\section{Results}

Oligometastatic prostate cancer and outcome of MDT

Overall, 56 Studies from 2012 to 2020 were included. Study methods and designs are listed in Table 1 . The vast majority of the studies were retrospective case series with median follow-up times between 6 and 70 months. Oligometastasis was inconsistently defined, with three and five metastases as the mostly used cut-off value. The inconsistent definition between the studies reflects the ongoing debate and suggests the difficulty of capturing the oligometastatic state by the sheer number of metastases alone. Of note, even though in most studies a maximum of five metastases was used in the inclusion criteria, the majority of patients had one or two metastases.

Whether the number of metastases also has prognostic value within the collective of oligometastatic patients remains unclear. While some studies - possibly underpowered due to small patient cohorts - could not show any influence, the number of metastases had an impact on the outcome in other studies [6-12].

Data for local control (LC) and progression free survival (PFS) are shown in Table 1. LC rates ranged between 76 and $100 \%$ at 2 years. PFS was inconsistently defined, as biochemical progression, clinical progression or both. The reported PFS values ranged from 38 to $100 \%$ at 1 year and $22-83 \%$ at 2 years and median PFS rates ranged from 7 to 63 month. The ORIOLE Trial, (a randomized phase II study) compared observation and MDT, and showed a significant difference in the median PFS with MDT (not reached vs. 5.8 months; hazard ratio, 0.30) [13]. Due to the large number of small case series, patient collectives, therapies and predictive factors differed substantially. 

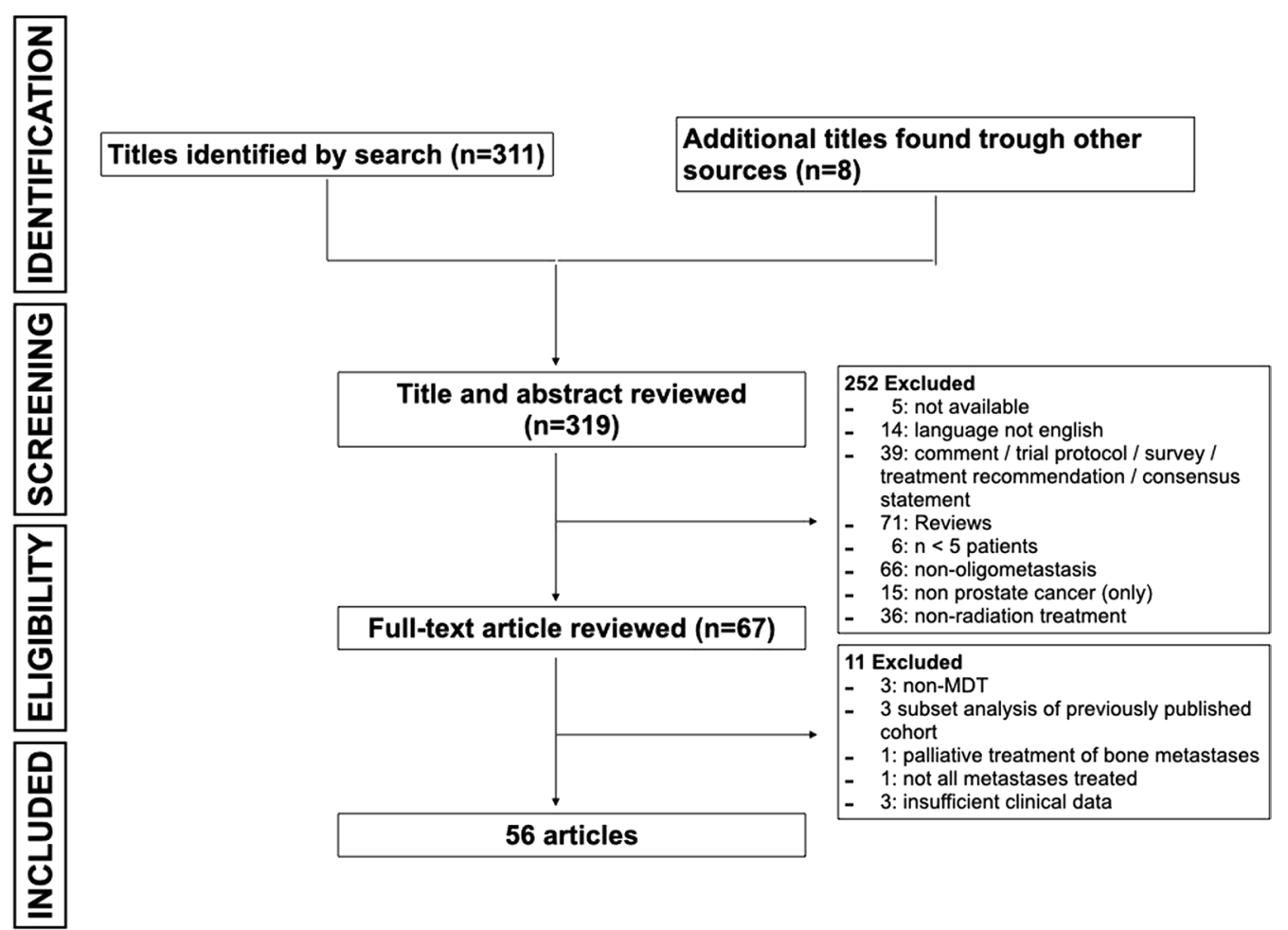

Fig. 2 Selection process

Hereinafter, some of these factors and their predictive value will be discussed in detail.

\section{Site of oligometastasis: bone versus lymph node}

The sites of treated metastases in the studies were mostly bone or lymph node. In the present review, twelve, seven and 37 studies with treatment of exclusively nodal metastases, bone metastases or both were included and investigated. In most studies including patients with nodal and bone metastases, the site of metastasis was not a predictive factor for the respective clinical outcomes [10, 12, 14-25]. In contrast, Fodor et al. reported a higher risk for clinical relapse in patients with extra-pelvic lymph nodes metastases compared with pelvic lymph node lesions and in the studies of Schick et al. and Deek et al. a trend for better biochemical progression-free survival (BPFS) was shown in patients with lymph node metastases compared with those with bone metastases [6, 26, 27]. In addition, the largest study to date based on prospectively collected data based on patients treated on clinical trials, demonstrated that the presence of bone metastases was associated with a worse survival compared to lymph node metastases in MPC [28]. Hence, it is not surprising that in the recently published APCCC report, the majority of experts voted for the distinction of these two kinds of metastatic patterns [29]. However, since encouraging clinical outcomes of studies with exclusively bone metastases were reported, with 2-year LC and PFS rates of $76-100 \%$ and $27-38 \%$, respectively, these patients may benefit from MDT and should not be excluded [8, 30-35].

\section{Imaging methods}

Due to the lack of predictive biomarkers, the definition of oligometastasis is currently based on the sheer number of metastases as determined by imaging, underscoring the critical importance of reliable imaging. Staging with ${ }^{68} \mathrm{Ga}$-prostate-specific membrane antigen PET/CT (PSMA PET/CT) appears to show the highest detection rates of metastases compared to other imaging modalities till now [36]. High detection rates of $15-58 \%$, $25-73 \%$ and $69-100 \%$ were reported for PSA ranges of $0.2-0.5 \mathrm{ng} / \mathrm{ml}, 0.5-1.0 \mathrm{ng} / \mathrm{ml}$ and $1-2 \mathrm{ng} / \mathrm{ml}$, respectively [37-41]. Compared to Choline PET/CT, PSMA PET/CT is substantially more sensitive, especially for low PSA values less than $2 \mathrm{ng} / \mathrm{ml}[42,43]$.

Therefore, due to the lower detection rates in studies that did not use PSMA PET/CT as imaging, many patients may have been yet undiagnosed polymetastatic disease and were consequently understaged [44]. In fact, even staging with PSMA PET/CT cannot exclude 


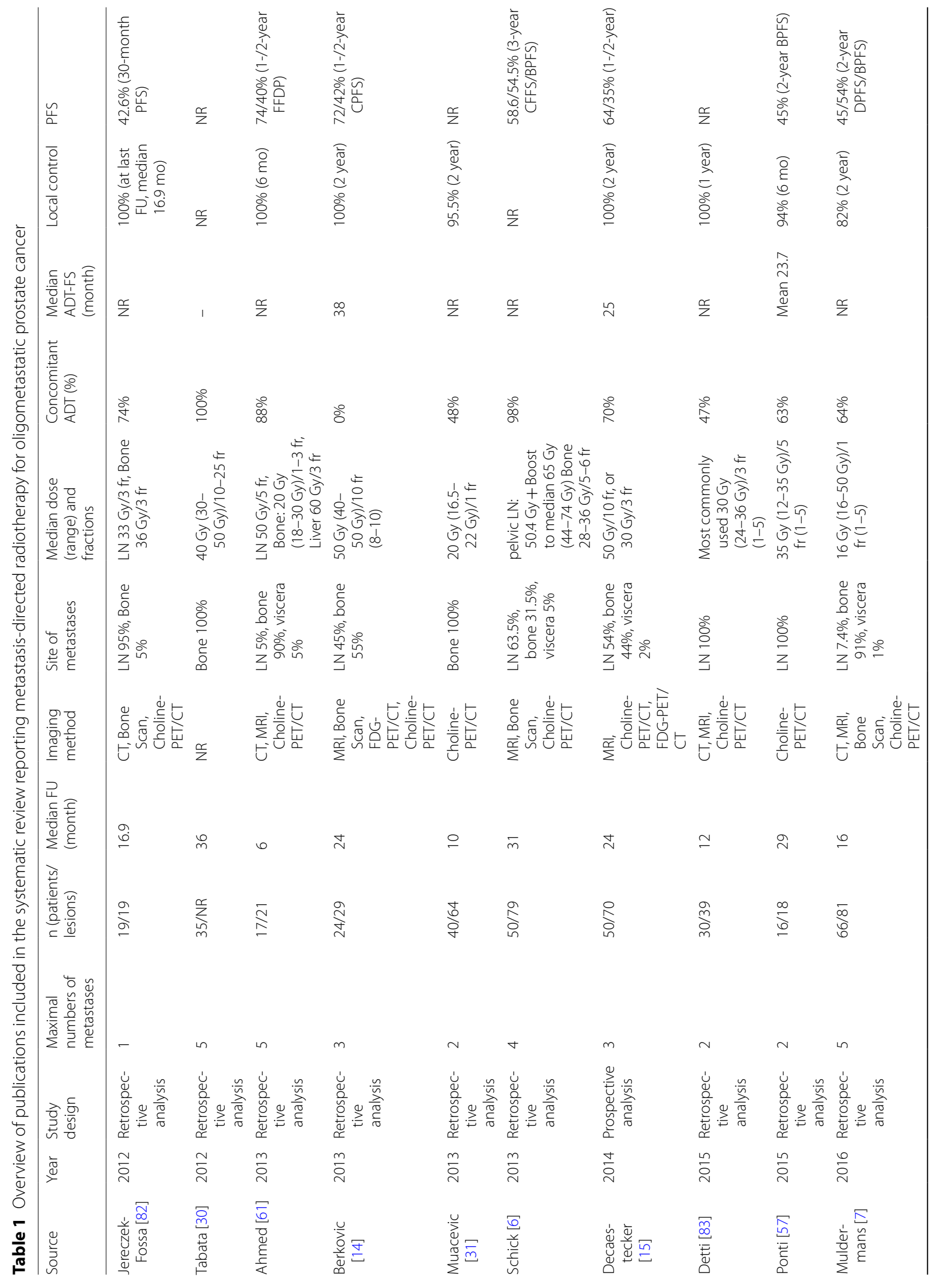


Rogowski et al. Radiat Oncol ～(2021) 16:50

Page 5 of 16

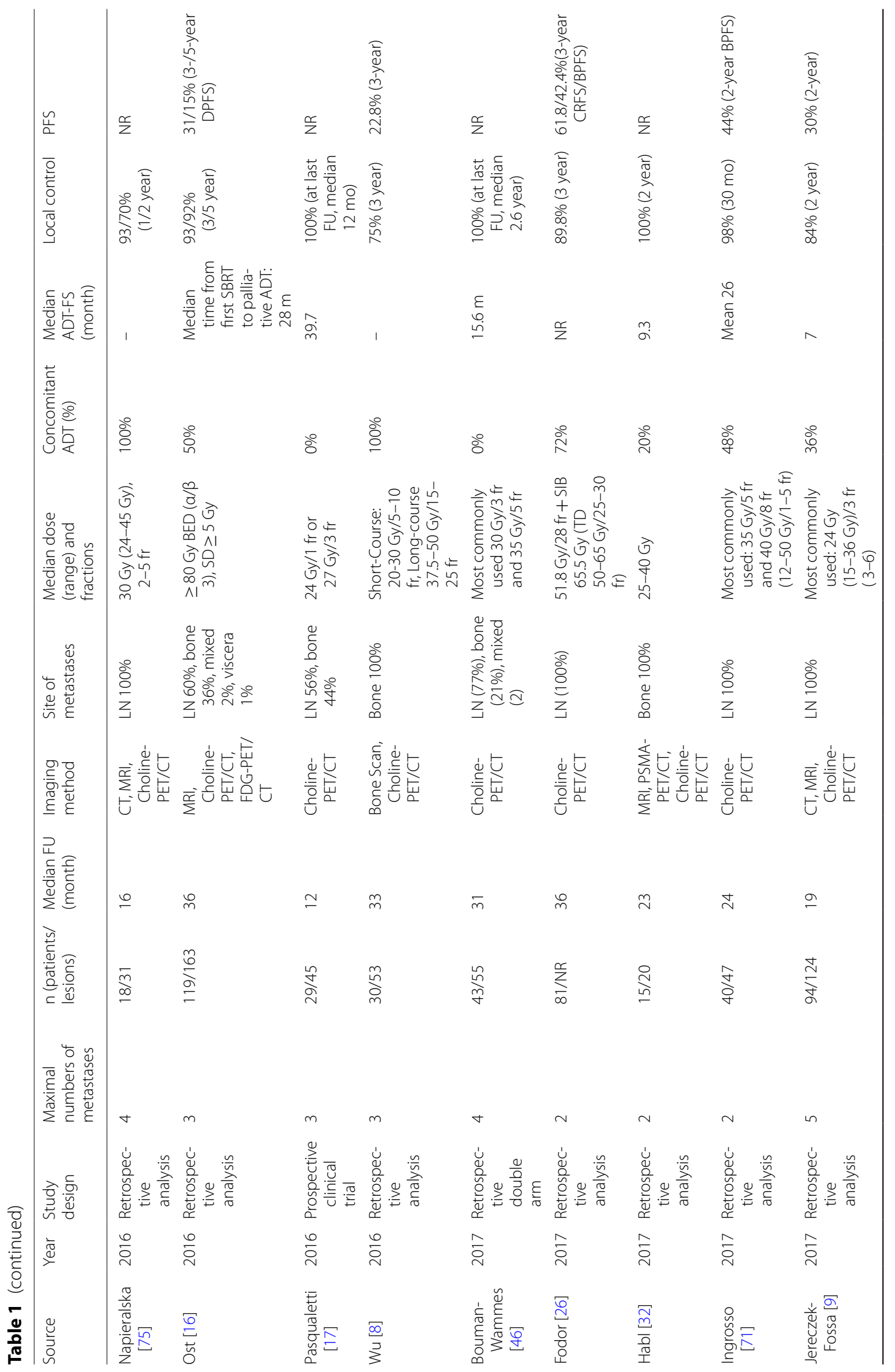




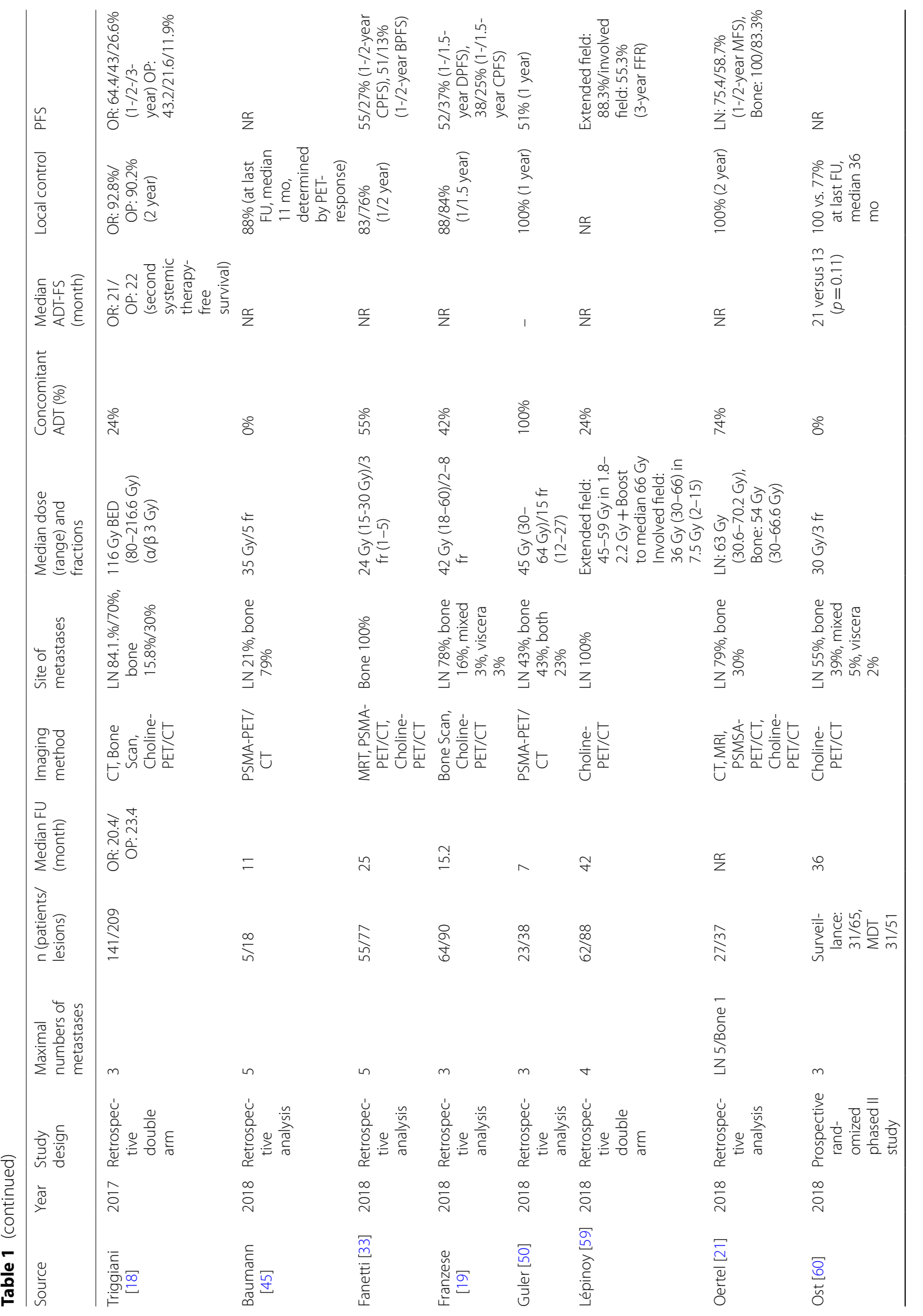


Rogowski et al. Radiat Oncol

(2021) 16:50

Page 7 of 16

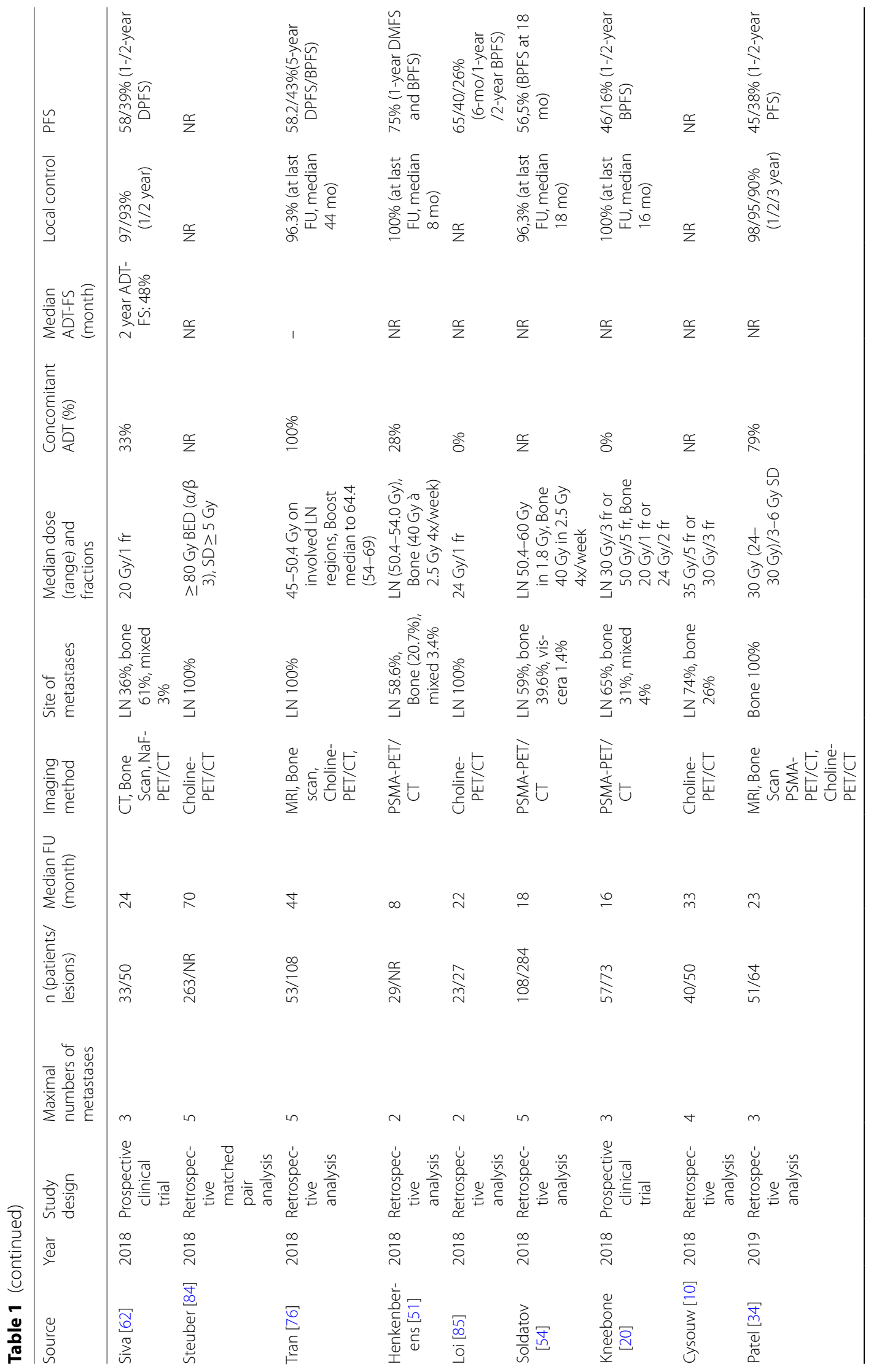




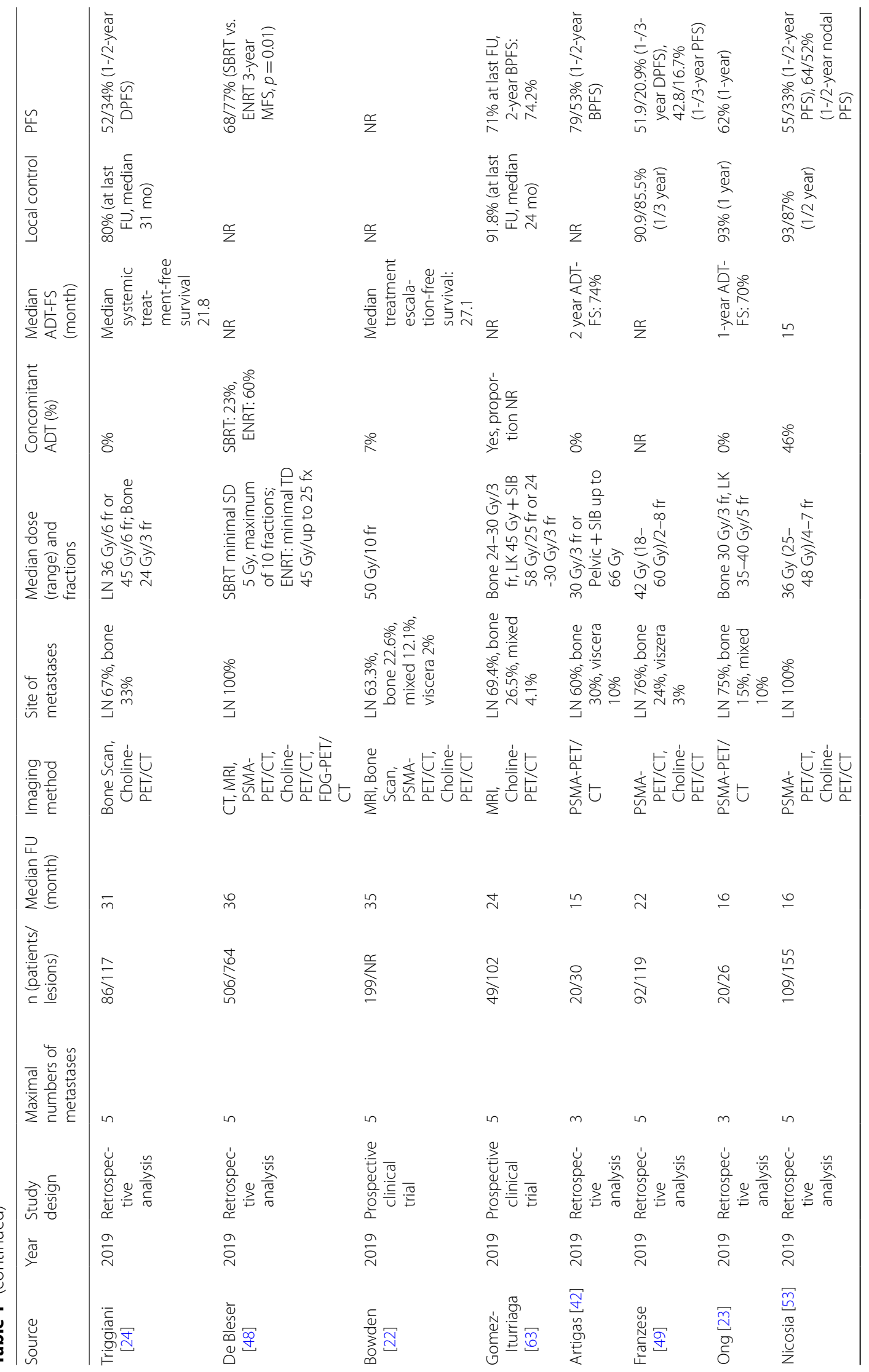




\begin{tabular}{|c|c|c|c|c|c|c|c|c|c|}
\hline 뜸 & 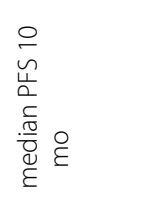 & 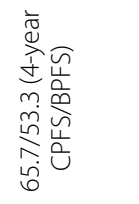 & 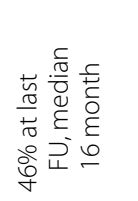 & 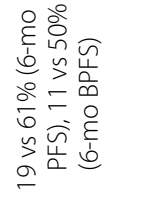 & 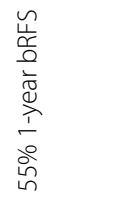 & 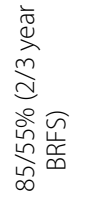 & 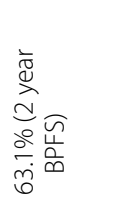 & 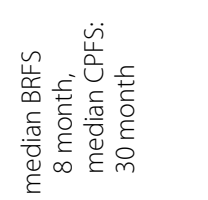 & 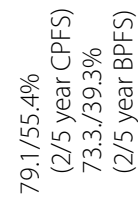 \\
\hline & $\frac{\mathscr{c}}{z}$ & 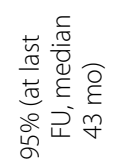 & 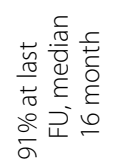 & $\begin{array}{l}\text { oे } \\
\xi \\
\hat{j} \\
\circ \\
o \\
o \\
\infty \\
o\end{array}$ & $\frac{\Re}{z}$ & 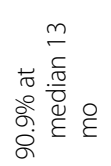 & 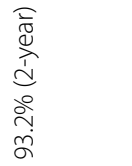 & 爱 & 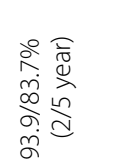 \\
\hline 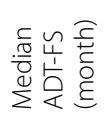 & 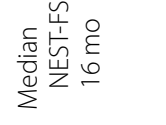 & I & $\stackrel{\Upsilon}{z}$ & $\stackrel{\propto}{z}$ & $\stackrel{+}{m}$ & $\stackrel{\stackrel{n}{m}}{=}$ & $\stackrel{\frac{c}{z}}{z}$ & $\begin{array}{l}\text { F } \\
\text { है } \\
\text { हो } \\
\stackrel{0}{0}\end{array}$ & $\stackrel{\Upsilon}{z}$ \\
\hline 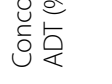 & $\stackrel{\Upsilon}{z}$ & $\stackrel{\circ}{\circ}$ & 今े & ஓे & $\begin{array}{l}\stackrel{8}{\circ} \\
\text { ó }\end{array}$ & $\frac{9}{6}$ & & $\frac{2}{6}$ & $\stackrel{\circ}{\stackrel{\circ}{\alpha}}$ \\
\hline 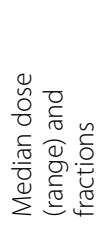 & 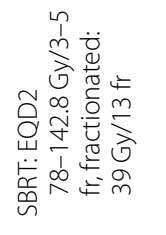 & $\begin{array}{l}\vec{J} \\
\forall\end{array}$ & 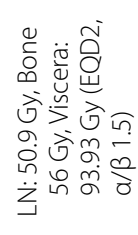 & 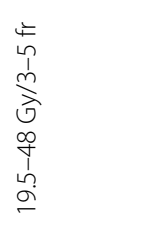 & 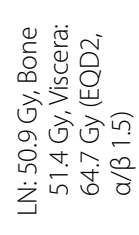 & 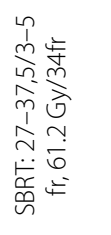 & 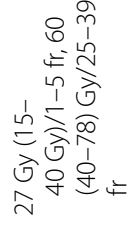 & 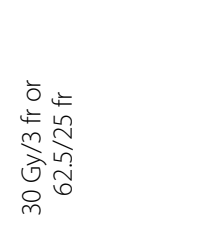 & 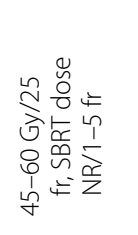 \\
\hline 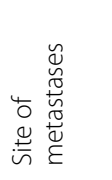 & 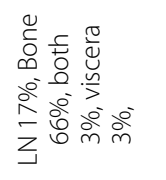 & 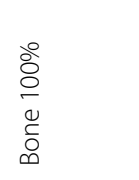 & 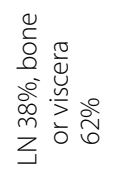 & 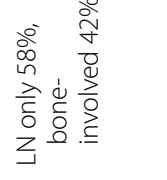 & 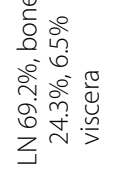 & 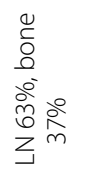 & 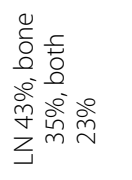 & 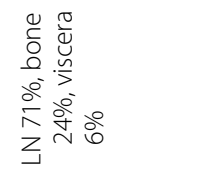 & 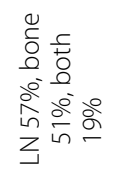 \\
\hline 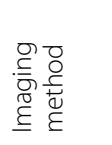 & 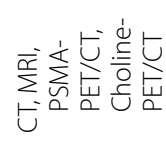 & 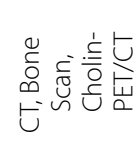 & 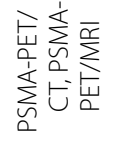 & 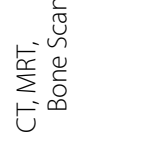 & 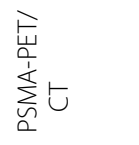 & 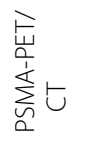 & 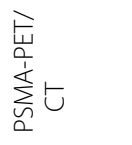 & 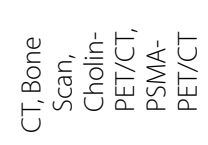 & 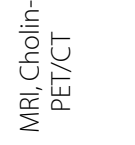 \\
\hline$\sum^{\infty}{ }^{\circ}$ है & $\stackrel{\infty}{-}$ & f & $\stackrel{\bullet}{\circ}$ & $\stackrel{a}{\llcorner}$ & $\stackrel{\bullet}{\circ}$ & $\stackrel{\bullet}{\sim}$ & $\ddot{\sim}$ & 年 & $\stackrel{\circ}{n}$ \\
\hline 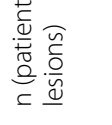 & $\stackrel{\text { 年 }}{\text { ) }}$ & $\underset{\text { ñ }}{\bar{n}}$ & $\stackrel{\stackrel{m}{m}}{m}_{n}^{m}$ & 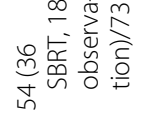 & 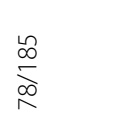 & $\stackrel{\infty}{\infty}_{\infty}^{\infty}$ & 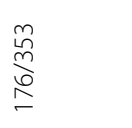 & 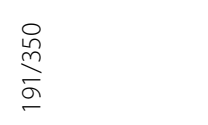 & $\underset{m}{\stackrel{a}{k}}$ \\
\hline 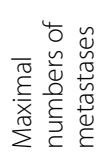 & $m$ & $\sim$ & in & $m$ & 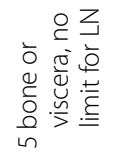 & in & in & n & in \\
\hline 중들 & 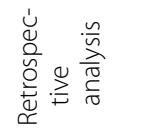 & 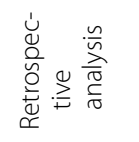 & 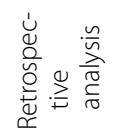 & 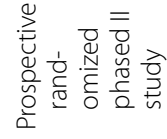 & 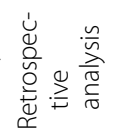 & 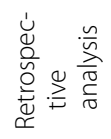 & 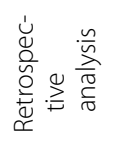 & 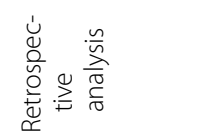 & 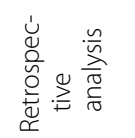 \\
\hline 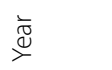 & 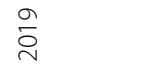 & 尺્તి & ڤ్ & ્ֻટి & ڤ్ & ڤ్ & ्ֻञ & 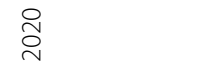 & ્ֻণ \\
\hline$\stackrel{\circlearrowright}{ٍ}$ & 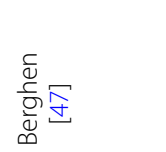 & 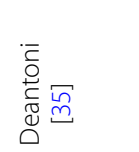 & 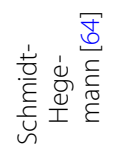 & 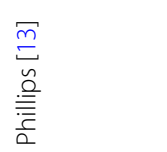 & 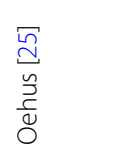 & 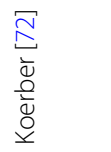 & $\begin{array}{l}\text { E } \\
\text { N } \\
\stackrel{N}{\underline{I}} \\
\text { 至 }\end{array}$ & $\begin{array}{l}\infty \\
\infty \\
\stackrel{0}{n} \\
0 \\
\stackrel{0}{0} \\
0\end{array}$ & 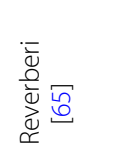 \\
\hline
\end{tabular}




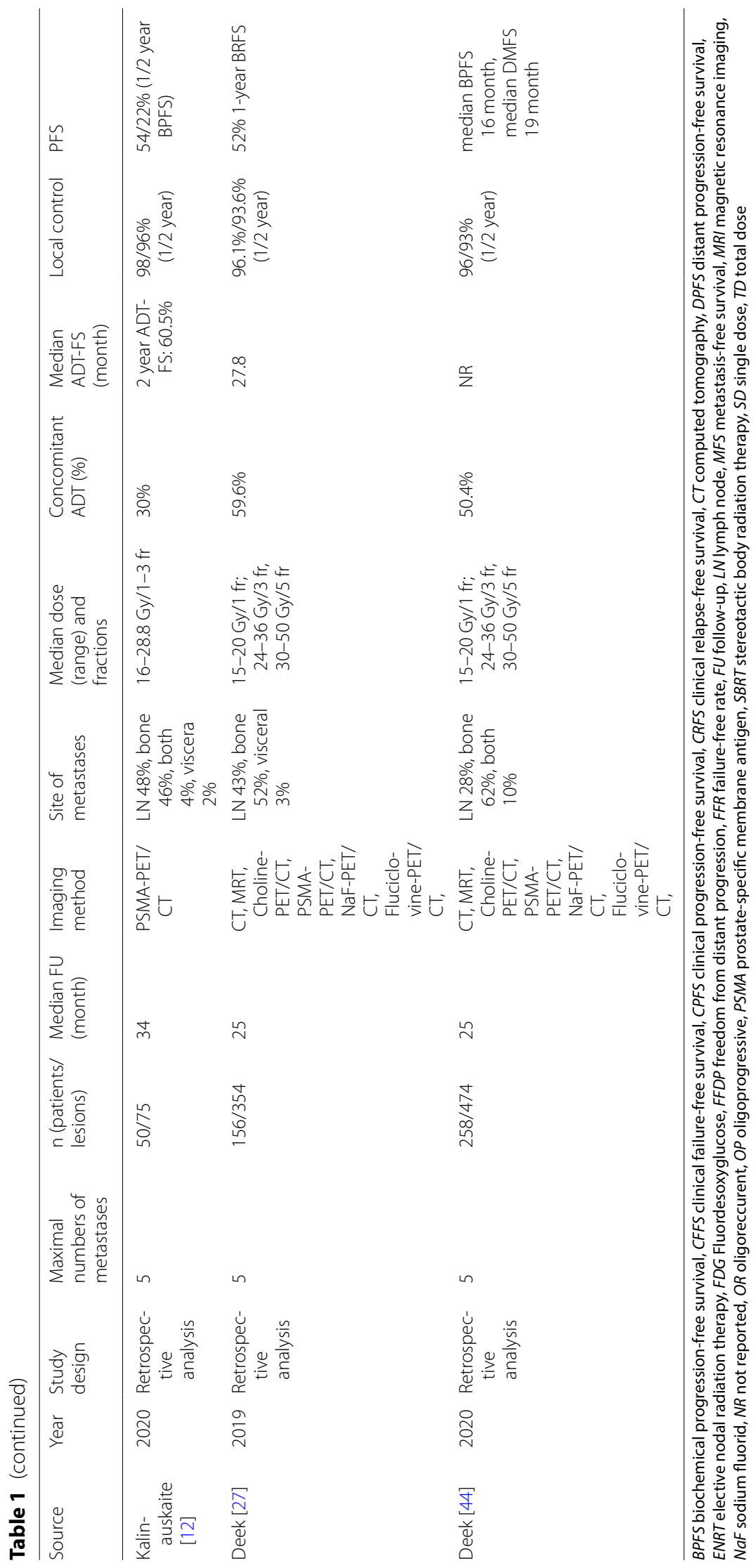


this possibility, but it can be assumed that this modality comes closest to defining a "true" oligometastatic state.

Two of the included studies investigated staging with choline or PSMA PET/CT as predictive factor in univariate analysis but failed to detect any impact of imaging on LC, PFS, OS or treatment escalation [19, 22]. However, small case numbers may limit the statistic power to prove a significant difference.

Despite the absence of definitive evidence for superiority of PSMA PET/CT in the oligometastatic setting, there has been a remarkable increase in use of ${ }^{68} \mathrm{Ga}$-PSMA PET/CT imaging in recent years. While $17 \%$ of the studies in this review published in 2017 used at least in part PSMA PET/CT, it was $47 \%$ and $78 \%$ of the studies in 2018 and 2019 [20-23, 32-34, 42, 45-55]. Being in line with these data, the panelists of APCCC recommended PSMA PET/CT to confirm the diagnosis of an oligometastatic disease after radical treatment [5]. A PSA threshold of 0.3 to $0.83 \mathrm{ng} / \mathrm{ml}$ appears to be an optimal cut-off value for using PSMA PET/CT as staging [50, 51, 54].

\section{Synchronous versus metachronous disease}

As used in the literature, oligometastasis can be defined to be present if detected either synchronously at the time of diagnosis of the primary tumor or metachronously (at a later date). However, the former scenario was regarded by some experts simply as metastatic disease. Moreover, there is no consensus in literature on the exact interval between diagnosis of the primary tumor and detection of oligometastases to differentiate between metachronous versus occult synchronous disease. Nevertheless, a frequently used definition of metachronous disease is an interval of more than 6 months [56]. Although the vast majority of the studies included patients with recurrent, i.e. "metachronous" disease, the reported intervals between primary diagnosis and detection of metastases were often less than 6 months. These studies had therefore rather mixed populations with metachronous and synchronous metastatic disease.

The parameters "time between primary and detection of oligometastasis" or "time between primary and radiotherapy" were reported in 35 studies with a median time interval between 7 and 67 months (range 0-240 months). Only 13 studies evaluated and reported one of these parameters in univariate or regression analysis, nine of them found no impact on outcome $[15,19,20,22,24,26$, $48,49,57,58]$. In contrast, Lépinoy et al. showed that a dichotomous division of patients by interval between primary and oligometastasis of more or less than 5 years was predictive for failure in both univariate and multivariate analyses with better outcome for intervals longer than 5 years [59]. Similarly, Ong et al. reported a better distant progression-free survival with longer time intervals and Kalinauskaite found an improved treatment failure free-survival in patients with time to first metastasis longer than 36 months $[12,23]$. In accordance with this data, it seems rational that a longer interval between primary diagnosis and oligometastasis may indicate less aggressive tumor biology. Metachronous disease was also an inclusion criterion for the two major phase II studies STOMP and ORIOLE addressing MDT in metastatic prostate cancer $[13,60]$.

\section{Systemic therapies}

Since it is widely accepted that hormone-sensitive prostate cancer (HSPC) and castration-resistant prostate cancer (CRPC) are different entities in terms of tumor biology and prognosis, it is consequential that in most studies the status of hormone sensitivity was reported $[7,12,13,17,19,22,30,32,34,35,44,49,50,53,54,58$, 61-65]. In the study of Franzese et al. CRPC was an independent risk factor for inferior PFS compared to HSPC in multivariate analysis (HR 2.12, $p=0.021$ ) [19]. This was confirmed by the data reported by Patel et al. (HR 8.43, $p<0.001$ ) [34]. In addition, Guler and Deek reported a significant worse PFS in CRPC patients [27, 50]. The reasons could be the more aggressive tumor biology in CRPC or/and a worse response to MDT. In our opinion, HSPC and CRPC should be considered as two distinct subgroups for further studies of oligometastasis.

Little is reported about the influence of hormone sensitivity on LC rates. Deek et al. found a significant higher local failure rate in CRPC patients compared with HSPC patients and Franzese et al. confirmed CRPC as a predictive factor for worse LC in univariate analysis [19, 27]. However, this effect was no longer detectable in the multivariate analysis. LC rates in the mixed-group studies were similar to those in which only HSPC patients were included. The 2-year local control reported by Triggiani et al. was $92.8 \%$ and $90.2 \%$ for HSPC and CRPC, respectively, so that it can be concluded that SBRT was able to achieve an excellent LC rate in both CRPC and HSPC oligometastatic patients [18]. This is not surprising given the fact that most studies of RT palliation for bone metastases have reported high response rates [66].

The "standard of care" for MPC has been ADT alone until recently wherein combinations including other systemic agents such as abiraterone or docetaxel have been added [67-69]. Even more recently local irradiation of prostate has been to standard systemic treatment and shown to improve overall survival for men with de novo metastatic prostate cancer with low metastatic burden [70]. However, some patients refuse systemic treatment primarily due to fears concerning their potential side effects and their comorbidity. Thus, androgen deprivation therapy free survival (ADTFS) was introduced 
by some authors in HSPC patients and reported in several studies, which ranged between 7 and 66 months $[9,12,14-18,25,27,32,46,57,58,71,72]$. Similarly, in CRPC cohorts, systemic therapy-free survival and treatment escalation-free survival, ranging between 16 and 27 months, were also introduced in the management of prostate cancer and investigated in some studies [22, 24, $47]$. In the case of newly developed oligometastasis after the initial metastasis-directed therapy, a second and further SBRT was allowed in some of these studies.

Of particular note is the prospective randomized STOMP study, which showed a prolonged ADTFS with MDT compared to observation after a medial follow-up of 3 years (21 vs. 13 month) [60]. LC and biochemical progression-free time were also improved in the MDT group with comparable quality of life. In the prospective single-arm trial reported by Siva et al., the ADTFS rate was $48 \%$ at 2 years. On the other side, there is a clear body of evidence showing improved overall survival with ADT and its combination therapies in metastatic disease $[67,73,74]$. Thus, omitting ADT may be associated with a worse survival while temporarily delaying side effects. This point should also be taken into account in decisionmaking of treatment and in the context of informed decision making with patients. Indeed $75 \%$ of the panelists of APCCC recommended adding MDT to systemic therapies, instead of replacing them [29].

\section{Radiation response, dose and field size}

Baumann et al. examined the metabolic response rate in PSMA PET/CT after SBRT of bone metastases with $5 \times 7$ Gy [45]. $78 \%$ of the irradiated lesions showed a metabolic response, which correlated with the time interval between SBRT and the post-therapeutic PSMA PET/CT. The metabolic response rate was $100 \%$ when follow-up imaging was performed 5 months or longer after the radiation. Consequently, a time interval of at least 6 months was recommended for the post-therapeutic PSMA PET/ $\mathrm{CT}$ as response evaluation.

The used fractionation schemes were highly variable (Table 1) ranging from single-dose SBRT with 24 Gy over total doses of 20-50 Gy (or more) in several fractions by moderately hypofractionated or normofractionated schedules. The most common fractionation scheme was 30 Gy in three fractions. Although in general the LC rate was high with acceptable toxicities, the optimal fractionation scheme remains undefined.

Some studies fail to show that radiation dose is predictive of outcome [17, 21, 24-26, 33, 53, 75], however, Ost et al. found better local PFS in multivariate analysis with a biological effective dose (BED) $>100 \mathrm{~Gy}$, using an $\alpha / \beta$ value of 3 Gy [16]. This cut-off dose was supported by another study in which a BED $>100$ Gy resulted in prolonged systemic treatment-free survival in univariate analysis [24]. In addition, Hurmuz and colleagues showed a better progression free-survival with a BED $>108$ Gy [11]. Muldermans et al. reported a higher 2-year LC rate for SBRT with $\geq 18$ Gy compared to 16 Gy (95\% vs. $58 \%$, $p=0.001)$. In another study of 40 patients, a median single-fraction dose of $20 \mathrm{~Gy}$ was used. Local failure occurred only in two patients who were treated with a reduced SBRT dose, because of prior radiotherapy and/ or vicinity to dose-sensitive organs related at risk [7, 31]. Additionally, Schick et al. found a significantly improved BPFS for SBRT with $\mathrm{EQD}_{2}$ (equivalent dose in 2 Gy fractions) $>64$ Gy using an $\alpha / \beta$-value of 2 Gy (HR 0.37, $p=0.034$ ) [6]. Although these observations may be considered "first hints" for defining the optimal dose, which should be taken into-account in the designing of further clinical trials, caution must be exercised in assuming that these post hoc studies are definitive due to issues related to major patient selection biases.

Regarding MDT of lymph node metastases, a distinction must be made between SBRT of the affected lymph nodes only and prophylactic elective nodal radiation therapy (ENRT) of the (loco)-regional lymph node station. ENRT usually involves using conventionally fractionated (i.e. 1.8-2.0 Gy) to imaging negative nodes to 45-50 Gy with a boost to the affected (i.e. PET positive) lymph nodes $[6,26,76]$. SBRT of lymph node metastasis was performed in a single fraction or hypofractionated with doses between 24 and 50 Gy in 3-10 fractions. Some studies reported a type of "involved field" irradiation without inclusion of the whole ipsilateral lymphatic drainage $[21,51,54]$. The doses used were $45-60$ Gy with a boost up to total doses ranging from 63 to $74 \mathrm{~Gy}$.

In two studies, the authors directly compared SBRT to ENRT plus Boost: Lépinoy et al. compared SBRT of affected lymph nodes mostly using 36 Gy in 5 fractions to conventionally fractionation extended field irradiation of the whole pelvis [59]. The use of ENRT was associated with a significantly longer failure-free time, albeit with a little more acute gastrointestinal toxicity. Their results were confirmed by De Bleser et al., who also reported fewer nodal recurrences and higher late toxicity in the ENRT group [48]. These findings and the pattern of progression described below support the hypothesis that in some cases, despite improved imaging sensitivity, the extent of metastasis, especially the spreading of microscopic cancer cells, is underestimated.

\section{Pattern of progression}

Distant/regional progression-free survival after MDT was $27-45 \%$ after 2 years $[15,51,54,62,63]$. Of the patients, who relapsed after the initial MDT, 50-91\% relapsed again in an oligometastatic pattern (as defined 
in the initial definition of oligometastasis in each study) $[15,54]$. A second, third and fourth course of SBRT was administered in some studies without increased toxicity $[12,15,51,54,58,62,63,65]$. In the trials using SBRT for MDT, recurrences occurred mostly in the same organ system, in lymph nodes or bone, respectively $[15,17$, 44]. Moreover, Nicosia et al. described that the majority of patients with nodal recurrence after SBRT suffered a lymph node relapse, which was out of but close to the radiation fields [53]. Soldatov et al. reported a shift from iliac lymph node metastases to retroperitoneal lymph node metastases or from retroperitoneal to distant lymph node metastases and bone metastases in patients with oligometastatic lymph nodes treated with ENRT [54]. This might be explained by the coverage of adjacent lymph nodes or elective lymph node stations. Moreover, the radiation dose for elective lymph node stations in the ENRT approach seems to be sufficient to eliminate the microscopic tumor cells, in principle favoring extended irradiation fields in this regard. However, less toxicities and the feasibility of repeated radiotherapy and possibly an enhanced immune response as shown in the ORIOLE trial potentially supporting the rationale for the use of SBRT alone [13].

\section{Conclusion and future perspectives}

The present review summarizes the available evidence on MDT in patients with what is commonly called "oligometastatic" prostate cancer. Unfortunately, there is a lack of consistency as to how "oligometastatic" disease is defined how it was treated, and the endpoints used to assess outcomes. In addition, due to rapidly evolving nature of imaging, the complexities involved in determining optimal management of oligometastatic prostate cancer diseases cannot be resolved today. Nonetheless, low morbidity and high local control rates have been reported with a considerable proportion of patients (22$83 \%$ ) remained progression-free for 2 years. With its relatively high sensitivity and specificity (compared to other imaging approaches), PSMA PET/CT was increasingly used for staging and for defining this entity. Although to date there is no randomized data demonstrating a better clinical outcome by using PSMA PET/CT for oligometastatic disease, it can be assumed that the higher detection rate will allow more patients to be diagnosed earlier in the metastatic course. This is supported by the multicenter retrospective cohort study of Mazzola and colleagues, in which PSMA-PET-guided SBRT for oligorecurrent castration-sensitive PC lead to a higher rate of ADT-free patients when compared with the 18F-cholinePET cohort [77].

Till now, the definition of oligometastasis was based on the sheer number of metastases, without taking into account the inhomogeneous biologic characters of cancer diseases and the potentially critical distinction between synchronous and metachronous metastasis. This may explain the inconsistencies in the results reported in different studies. The limitations associated with a definition based solely by the number of "oligometastasis" and on imperfect imaging, means that we are doomed to have an imperfect definition. Other risk factors, such as Gleason score, PSA kinetics, should also be involved in the differentiation of the oligometastatic diseases in the future. Moreover, given its rapid evolvement in the last years and great potential for precise risk stratification, novel biomarkers may be helpful for identifying patients who benefit from MDT.

Treatment regimens varied widely in radiation dose and field size. A possible cut-off value of radiation dose could be considered at BED > 100 Gy. In lymph node irradiation, a more extensive ENRT seemed to be superior to SBRT in terms of loco-regional disease control, albeit at cost of slightly higher incidence of acute toxicity. With the recent completed enrollment of $>2500$ patients on to RTOG 0924 trial (evaluating the impact of prophylactic nodal irradiation) and a planned analysis in 2023), the understanding and management of micro-metastatic disease (possibly below the resolution of PSMA-PET) is likely to change.

Although, the role of ADT in the oligometastatic patients treated with MDT remains an unsolved issue, it seems most highly implausible that RT alone will ever be adequate. While there is evidence from a phase II study for a prolonged ADTFS with MDT in oligometastatic patients, concurrent ADT seemed to improve the effectivity of MDT in some other retrospective series. Thus, future studies should be designed to clarify the role of ADT in oligometastatic diseases, especially in the context of the widespread usage of MDT. It may be possible that different subgroup of oligometastatic patients benefit from different therapy approach, which also need to be addressed. Several prospective studies on MDT in oligometastatic prostate cancer are ongoing [36, 78-81]. Their final results will hopefully provide more solid evidence for the optimal usage of MDT in clinical practice.

\section{Abbreviations}

ADT: Androgen deprivation therapy; ADTFS: Androgen deprivation therapyfree survival; APCCC: Advanced prostate cancer consensus conference; BPFS: Biochemical progression-free survival; BED: Biologically effective dose; $\mathrm{CT}$ : Computed tomography; CRPC: Castrate-resistant prostate cancer; ENRT: Elective nodal radiotherapy; HSPC: Hormone-sensitive prostate cancer; LC: Local control; MDT: Metastasis-directed therapy; MPC: Metastatic prostate cancer; PET: Positron emission tomography; PET/CT: Positron emission tomography/ computed tomography; PRISMA: Preferred reporting items for systematic reviews and meta-analysis; PFS: Progression-free survival; ${ }^{68} \mathrm{Ga}-\mathrm{PSMA}:{ }^{68} \mathrm{Gal}-$ lium-prostate-specific membrane antigen; PC: Prostate cancer; PSA: Prostate specific antigen; RT: Radiotherapy; SBRT: Stereotactic body radiation therapy. 


\section{Acknowledgements \\ Not applicable.}

\section{Authors' contributions}

$\mathrm{PR}$ and $\mathrm{ML}$ conceived the original idea and took the lead in writing the manuscript, NS-H, RB, CT and RS contributed to the interpretation oft he results, $M R$ contributed to the final version oft he manuscript, provided critical feedback and helped shape the research, AB, CS and CB helphed supervise the project. All authors read and approved the final manuscript.

\section{Funding}

No funding was received.

\section{Availability of data and materials}

Research data are stored in an institutional repository and will be shared upon request to the corresponding author.

\section{Declarations}

Ethics approval and consent to participate

Not neccesary.

\section{Consent for publication}

Not applicable.

\section{Competing interests}

CB reports a research grant from ViewRay and speakers honoraria from Takeda during the conduct of the study.

\section{Author details}

1 Department of Radiation Oncology, University Hospital, LMU Munich, Marchioninistr. 15, 81377 Munich, Germany. ${ }^{2}$ Department of Radiation Oncology, UCSF Helen Diller Family Comprehensive Cancer Center, 1600 Divisadero Street, Suite H 1031, San Francisco, CA 94143-1708, USA. ${ }^{3}$ Department of Urology, University Hospital, LMU Munich, Marchioninistr. 15, 81377 Munich, Germany. ${ }^{4}$ German Cancer Consortium (DKTK), Munich, Germany.

Received: 8 February 2021 Accepted: 24 February 2021

Published online: 09 March 2021

\section{References}

1. Bray F, Ferlay J, Soerjomataram I, Siegel RL, Torre LA, Jemal A. Global cancer statistics 2018: GLOBOCAN estimates of incidence and mortality worldwide for 36 cancers in 185 countries. CA Cancer J Clin. 2018;68(6):394-424

2. Cornford P, Bellmunt J, Bolla M, Briers E, De Santis M, Gross T, et al. EAU-ESTRO-SIOG guidelines on prostate cancer. Part II: treatment of relapsing, metastatic, and castration-resistant prostate cancer. Eur Urol. 2017;71(4):630-42.

3. Hellman, Weichselbaum. Oligometastases. 1995.

4. Fossati N, Suardi N, Gandaglia G, Bravi CA, Soligo M, Karnes RJ, et al. Identifying the optimal candidate for salvage lymph node dissection for nodal recurrence of prostate cancer: results from a large, multi-institutional analysis. Eur Urol. 2019;75(1):176-83.

5. Gillessen S, Attard G, Beer TM, Beltran H, Bossi A, Bristow R, et al. Management of patients with advanced prostate cancer: the report of the advanced prostate cancer consensus conference APCCC 2017 [figure presented]. Eur Urol. 2018;73(2):178-211.

6. Schick U, Jorcano S, Nouet P, Rouzaud M, Vees H, Zilli T, et al. Androgen deprivation and high-dose radiotherapy for oligometastatic prostate cancer patients with less than five regional and/or distant metastases. Acta Oncol. 2013;52(8):1622-8.

7. Muldermans JL, Romak LB, Kwon ED, Park SS, Olivier KR. Stereotactic body radiation therapy for oligometastatic prostate cancer. Int J Radiat Oncol Biol Phys. 2016;95(2):696-702.

8. Wu JX, Lin LM, He JY, Hong L, Li JL. Radiotherapy combined with androgen deprivation for bone oligometastases after primary curative radiotherapy for prostate cancer. Medicine (United States). 2016;95(6):1-6.
9. Jereczek-Fossa BA, Fanetti G, Fodor C, Ciardo D, Santoro L, Francia $\mathrm{CM}$, et al. Salvage stereotactic body radiotherapy for isolated lymph node recurrent prostate cancer: single institution series of 94 consecutive patients and 124 lymph nodes. Clin Genitourin Cancer. 2017;15(4):e623-32

10. Cysouw M, Bouman-Wammes E, Hoekstra O, van den Eertwegh A, Piet $\mathrm{M}$, van Moorselaar J, et al. Prognostic value of [18 F]-fluoromethylcholine positron emission tomography/computed tomography before stereotactic body radiation therapy for oligometastatic prostate cancer. Int J Radiat Oncol Biol Phys. 2018;101(2):406-10.

11. Hurmuz P, Onal C, Ozyigit G, Igdem S, Atalar B, Sayan H, et al. Treatment outcomes of metastasis-directed treatment using (68)Ga-PSMA-PET/ CT for oligometastatic or oligorecurrent prostate cancer: Turkish Society for Radiation Oncology group study (TROD 09-002). Strahlentherapie und Onkologie: Organ der Deutschen Rontgengesellschaft [et al]. 2020;196(11):1034-43.

12. Kalinauskaite G, Senger C, Kluge A, Furth C, Kufeld M, Tinhofer I, et al. 68Ga-PSMA-PET/CT-based radiosurgery and stereotactic body radiotherapy for oligometastatic prostate cancer. PLoS ONE. 2020;15(10):e0240892.

13. Phillips R, Shi WY, Deek M, Radwan N, Lim SJ, Antonarakis ES, et al. Outcomes of observation vs stereotactic ablative radiation for oligometastatic prostate cancer: the ORIOLE phase 2 randomized clinical trial. JAMA Oncol. 2020;6(5):650-9.

14. Berkovic P, De Meerleer G, Delrue L, Lambert B, Fonteyne V, Lumen N, et al. Salvage stereotactic body radiotherapy for patients with limited prostate cancer metastases: deferring androgen deprivation therapy. Clin Genitourin Cancer. 2013:11(1):27-32.

15. Decaestecker K, De Meerleer G, Lambert B, Delrue L, Fonteyne V, Claeys T, et al. Repeated stereotactic body radiotherapy for oligometastatic prostate cancer recurrence. Radiat Oncol. 2014;9(1):1-10.

16. Ost P, Jereczek-Fossa BA, As NV, Zilli T, Muacevic A, Olivier K, et al. Progression-free survival following stereotactic body radiotherapy for oligometastatic prostate cancer treatment-naive recurrence: a multiinstitutional analysis. Eur Urol. 2016;69(1):9-12.

17. Pasqualetti F, Panichi M, Sainato A, Matteucci F, Galli L, Cocuzza P, et al. [18F]Choline PET/CT and stereotactic body radiotherapy on treatment decision making of oligometastatic prostate cancer patients: preliminary results. Radiat Oncol. 2016;11(1):1-8.

18. Triggiani L, Alongi F, Buglione M, Detti B, Santoni R, Bruni A, et al. Efficacy of stereotactic body radiotherapy in oligorecurrent and in oligoprogressive prostate cancer: new evidence from a multicentric study. $\mathrm{Br} J$ Cancer. 2017:116(12):1520-5

19. Franzese C, Agostino GD, Navarria P, Franceschini D, Zucali PA, Brina LD, et al. The efficacy of Stereotactic body radiation therapy and the impact of systemic treatments in oligometastatic patients from prostate cancer. Cancer Med. 2018;7(July):1-8.

20. Kneebone A, Hruby G, Ainsworth H, Byrne K, Brown C, Guo L, et al. Stereotactic body radiotherapy for oligometastatic prostate cancer detected via prostate-specific membrane antigen positron emission tomography. Eur Urol Oncol. 2018;1:531-7.

21. Oertel M, Scobioala S, Kroeger K, Baehr A, Stegger L, Haverkamp U, et al. Worth a local treatment? - analysis of modern radiotherapy concepts for oligometastatic prostate cancer. Radiat Oncol. 2018:d·7-14.

22. Bowden P, See AW, Frydenberg M, Haxhimolla H, Costello AJ, Moon D, et al. Fractionated stereotactic body radiotherapy for up to five prostate cancer oligometastases: interim outcomes of a prospective clinical trial. Int J Cancer. 2019;146:1-9.

23. Ong WL, Koh TL, Lim Joon D, Chao M, Farrugia B, Lau E, et al. Prostatespecific membrane antigen-positron emission tomography/computed tomography (PSMA-PET/CT)-guided stereotactic ablative body radiotherapy for oligometastatic prostate cancer: a single-institution experience and review of the published literature. BJU Int. 2019;124:19-30.

24. Triggiani L, Mazzola R, Maria S, Gianluca M, Paolo I, Trippa F, et al. Metastasis-directed stereotactic radiotherapy for oligoprogressive castration-resistant prostate cancer: a multicenter study. World J Urol. 2019:37:2631-7.

25. Oehus AK, Kroeze SGC, Schmidt-Hegemann NS, Vogel MME, Kirste S, Becker J, et al. Efficacy of PSMA ligand PET-based radiotherapy for recurrent prostate cancer after radical prostatectomy and salvage radiotherapy. BMC Cancer. 2020;20(1):362. 
26. Fodor A, Berardi G, Fiorino C, Picchio M, Busnardo E, Kirienko M, et al. Toxicity and efficacy of salvage carbon 11-choline positron emission tomography/computed tomography-guided radiation therapy in patients with lymph node recurrence of prostate cancer. BJU Int. 2017;119(3):406-13.

27. Deek MP, Yu C, Phillips R, Song DY, Deville C, Greco S, et al. Radiation therapy in the definitive management of oligometastatic prostate cancer: the Johns Hopkins experience. Int J Radiat Oncol Biol Phys. 2019;105(5):948-56.

28. Halabi S, Kelly WK, Ma H, Zhou H, Solomon NC, Fizazi K, et al. Meta-analysis evaluating the impact of site of metastasis on overall survival in men with castration-resistant prostate cancer. J Clin Oncol. 2016:34(14):1652-9.

29. Gillessen S, Attard G, Beer TM, Beltran H, Bjartell A, Bossi A, et al. Management of patients with advanced prostate cancer: report of the advanced prostate cancer consensus conference 2019. Eur Urol. 2020;77(4):508-47.

30. Tabata Kl, Niibe Y, Satoh T, Tsumura H, Ikeda M, Minamida S, et al. Radiotherapy for oligometastases and oligo-recurrence of bone in prostate cancer. Pulm Med. 2012;2012:6-11.

31. Muacevic A, Kufeld M, Rist C, Wowra B, Stief C, Staehler M. Safety and feasibility of image-guided robotic radiosurgery for patients with limited bone metastases of prostate cancer. Urol Oncol Semin Orig Investig. 2013;31(4):455-60.

32. Habl G, Straube C, Schiller K, Duma MN, Oechsner M, Kessel KA, et al. Oligometastases from prostate cancer: local treatment with stereotactic body radiotherapy (SBRT). BMC Cancer. 2017;17(1):1-10.

33. Fanetti G, Marvaso G, Ciardo D, Rese A, Ricotti R, Rondi E, et al. Stereotactic body radiotherapy for castration-sensitive prostate cancer bone oligometastases. Med Oncol. 2018;35(5):1-8.

34. Patel PH, Lee C, Alison C, Mansour CT, Nicholas S. Stereotactic body radiotherapy for bone oligometastatic disease in prostate cancer. World J Urol. 2019;37:2615-21.

35. Deantoni CL, Fodor A, Cozzarini C, Fiorino C, Brombin C, Di Serio C, et al. Prostate cancer with low burden skeletal disease at diagnosis: outcome of concomitant radiotherapy on primary tumor and metastases. Br J Radiol. 2020;93(1108):20190353.

36. Lancia A, Zilli T, Achard V, Dirix P, Everaerts W, Gomez-iturriaga A, et al. Oligometastatic prostate cancer: the game is afoot. Cancer Treat Rev. 2019;73(December 2018):84-90

37. Afshar-Oromieh A, Zechmann CM, Malcher A, Eder M, Eisenhut M, Linhart $\mathrm{HG}$, et al. Comparison of PET imaging with a 68Ga-labelled PSMA ligand and $18 \mathrm{~F}$-choline-based PET/CT for the diagnosis of recurrent prostate cancer. Eur J Nucl Med Mol Imaging. 2014;41(1):11-20.

38. Ceci F, Uprimny C, Nilica B, Geraldo L, Kendler D, Kroiss A, et al. 68GaPSMA PET/CT for restaging recurrent prostate cancer: which factors are associated with PET/CT detection rate? Eur I Nucl Med Mol Imaging. 2015;42(8):1284-94.

39. Eiber M, Maurer T, Souvatzoglou M, Beer AJ, Ruffani A, Haller B, et al. Evaluation of hybrid $<$ sup $>68</$ sup $>$ Ga-PSMA ligand PET/CT in 248 patients with biochemical recurrence after radical prostatectomy. J Nuc Med. 2015;56(5):668-74.

40. Schmidt-Hegemann NS, Fendler WP, Buchner A, Stief C, Rogowski P, Niyazi $M$, et al. Detection level and pattern of positive lesions using PSMA PET/ CT for staging prior to radiation therapy. Radiat Oncol. 2017;12(1):1-9.

41. Schmidt-Hegemann NS, Fendler WP, IIhan $H$, Herlemann A, Buchner A, Stief $\mathrm{C}$, et al. Outcome after PSMA PET/CT based radiotherapy in patients with biochemical persistence or recurrence after radical prostatectomy. Radiat Oncol (London, England). 2018;13(1):37.

42. Artigas P, Flamen C, Levillain FCH, Diamand ZWR, Gil SAT. Ga-PSMA PET/CT-based metastasis-directed radiotherapy for oligometastatic prostate cancer recurrence after radical prostatectomy. World J Urol. 2019;37(8):1535-42.

43. Zschaeck S, Lohaus F, Beck M, Habl G, Kroeze S, Zamboglou C, et al. PSMA-PET based radiotherapy: a review of initial experiences, survey on current practice and future perspectives. Radiat Oncol (London, England). 2018;13(1):90

44. Deek MP, Taparra K, Dao D, Chan L, Phillips R, Gao RW, et al. Patterns of recurrence and modes of progression after metastasis-directed therapy in oligometastatic castration-sensitive prostate cancer. Int J Radiat Oncol Biol Phys. 2020;109:387-95.
45. Baumann R, Koncz M, Luetzen U, Krause F, Dunst J. Oligometastases in prostate cancer: metabolic response in follow-up PSMA-PET-CTs after hypofractionated IGRT. Strahlenther Onkol. 2018;194(4):318-24.

46. Bouman-Wammes EW, van Dodewaard-De Jong JM, Dahele M, Cysouw MCF, Hoekstra OS, van Moorselaar RJA, et al. Benefits of using stereotactic body radiotherapy in patients with metachronous oligometastases of hormone-sensitive prostate cancer detected by [18F]fluoromethylcholine PET/CT. Clin Genitourin Cancer. 2017;15(5):e773-82.

47. Berghen C, Joniau S, Ost P, Poels K, Everaerts W, Decaestecker K, et al. Progression-directed therapy for oligoprogression in castration-refractory prostate cancer. Eur Urol Oncol. 2019;S2588-9311(19)30138-5.

48. De Bleser E, Jereczek-fossa BA, Pasquier D, Zilli T, As NV, Siva S, et al. Metastasis-directed therapy in treating nodal oligorecurrent prostate cancer : a multi-institutional analysis comparing the outcome and toxicity of stereotactic body radiotherapy and elective nodal radiotherapy. Eur Urol. 2019;76:1-8.

49. Franzese C, Di Brina L, D'Agostino G, Franceschini D, Comito T, De Rose $F$, et al. Predictive factors for survival outcomes of oligometastatic prostate cancer patients treated with metastases-directed therapy: a recursive partitioning-based analysis. J Cancer Res Clin Oncol. 2019;145(10):2469-79.

50. Guler OC, Engels B, Onal C, Everaert H, Van den Begin R, Gevaert T, et al. The feasibility of prostate-specific membrane antigen positron emission tomography(PSMA PET/CT)-guided radiotherapy in oligometastatic prostate cancer patients. Clin Transl Oncol. 2018;20(4):484-90.

51. Henkenberens C, von Klot CA, Ross TL, Bengel FM, Wester H-J, Merseburger AS, et al. 68Ga-PSMA ligand PET/CT-based radiotherapy in locally recurrent and recurrent oligometastatic prostate cancer. Strahlenther Onkol. 2016;192(7):431-9.

52. Kroeze SGC, Henkenberens C, Schmidt-Hegemann NS, Vogel MME, Kirste S, Becker J, et al. Prostate-specific membrane antigen positron emission tomography-detected oligorecurrent prostate cancer treated with metastases-directed radiotherapy: role of addition and duration of androgen deprivation. Eur Urol Focus. 2019;S2405-4569(19)30270-6.

53. Nicosia L, Franzese C, Mazzola R, Franceschini D, Rigo M, D’agostino G, et al. Recurrence pattern of stereotactic body radiotherapy in oligometastatic prostate cancer: a multi-institutional analysis. Strahlenther Onkol. 2019;196:213-21.

54. Soldatov A, Klot CAJV, Walacides D, Derlin T, Bengel FM, Ross TL, et al. Patterns of progression after 68 Ga-PSMA-ligand PET/CT-guided radiation therapy for recurrent prostate cancer. Int J Radiat Oncol Biol Phys. 2019;103(1):95-104.

55. Vogel MME, Kroeze SGC, Henkenberens C, Schmidt-Hegemann NS, Kirste $\mathrm{S}$, Becker J, et al. Prognostic risk classification for biochemical relapse-free survival in patients with oligorecurrent prostate cancer after [(68) Ga] PSMA-PET-guided metastasis-directed therapy. Eur J Nucl Med Mol Imaging. 2020;47(10):2328-38.

56. Guckenberger M, Lievens Y, Bouma AB, Collette L, Dekker A, deSouza NM, et al. Characterisation and classification of oligometastatic disease: a European Society for Radiotherapy and Oncology and European Organisation for Research and Treatment of Cancer consensus recommendation. Lancet Oncol. 2020;21(1):e18-28.

57. Ponti E, Ingrosso G, Carosi A, Di Murro L, Lancia A, Pietrasanta F, et al. Salvage stereotactic body radiotherapy for patients with prostate cancer with isolated lymph node metastasis: a single-center experience. Clin Genitourin Cancer. 2015;13(4):e279-84.

58. Devos G, Berghen C, Van Eecke H, Stichele AV, Van Poppel H, Goffin K, et al. Oncological outcomes of metastasis-directed therapy in oligorecurrent prostate cancer patients following radical prostatectomy. Cancers. 2020;12(8):2271.

59. Lépinoy A, Silva YE, Martin E, Bertaut A, Quivrin M, Aubignac L, et al. Salvage extended field or involved field nodal irradiation in 18F-fluorocholine PET/CT oligorecurrent nodal failures from prostate cancer. Eur J Nucl Med Mol Imaging. 2018:46:40-8.

60. Ost P, Reynders D, Decaestecker K, Fonteyne V, Lumen N, De Bruycker A, et al. Surveillance or metastasis-directed therapy for oligometastatic prostate cancer recurrence: a prospective, randomized, multicenter phase II trial. J Clin Oncol. 2017;36(5):446-53.

61. Ahmed KA, Barney BM, Davis BJ, Park SS, Kwon ED, Olivier KR. Stereotactic body radiation therapy in the treatment of oligometastatic prostate cancer. Fronti Oncol. 2013;2(November 2011):1-6. 
62. Siva S, Bressel M, Murphy DG, Shaw M, Chander S, Violet J, et al. Stereotactic abative body radiotherapy (SABR) for oligometastatic prostate cancer: a prospective clinical trial. Eur Urol. 2018;74(4):455-62.

63. Gomez-Iturriaga A, Casquero F, Piet O, Iratxe O, Rodeño E, Llarena R, et al. Outcomes after a first and/or second salvage treatment in patients with oligometastatic prostate cancer recurrence detected by (18-F) choline PET-CT. Eur J Cancer Care (Engl). 2019;28(November 2018):3-9.

64. Schmidt-Hegemann NS, Kroeze SGC, Henkenberens C, Vogel MME, Kirste S, Becker J, et al. Influence of localization of PSMA-positive oligometastases on efficacy of metastasis-directed external-beam radiotherapy-a multicenter retrospective study. Eur J Nucl Med Mol Imaging. 2020;47(8):1852-63.

65. Reverberi C, Massaro M, Osti MF, Anzellini D, Marinelli L, Montalto A, et al. Local and metastatic curative radiotherapy in patients with de novo oligometastatic prostate cancer. Sci Rep. 2020;10(1):17471.

66. Hartsell WF, Scott CB, Bruner DW, Scarantino CW, Ivker RA, Roach M 3rd, et al. Randomized trial of short- versus long-course radiotherapy for palliation of painful bone metastases. J Natl Cancer Inst. 2005;97(11):798-804

67. Fizazi K, Tran N, Fein L, Matsubara N, Rodriguez-Antolin A, Alekseev BY, et al. Abiraterone plus prednisone in metastatic, castration-sensitive prostate cancer. N Engl J Med. 2017;377(4):352-60.

68. James ND, de Bono JS, Spears MR, Clarke NW, Mason MD, Dearnaley DP, et al. Abiraterone for prostate cancer not previously treated with hormone therapy. N Engl J Med. 2017;377(4):338-51.

69. Kyriakopoulos CE, Chen YH, Carducci MA, Liu G, Jarrard DF, Hahn NM, et al. Chemohormonal therapy in metastatic hormone-sensitive prostate cancer: long-term survival analysis of the randomized phase III E3805 CHAARTED trial. J Clin Oncol. 2018;36(11):1080-7.

70. Parker CC, James ND, Brawley CD, Clarke NW, Hoyle AP, Ali A, et al. Radiotherapy to the primary tumour for newly diagnosed, metastatic prostate cancer (STAMPEDE): a randomised controlled phase 3 trial. Lancet (Lond, Engl). 2018;392(10162):2353-66.

71. Ingrosso G, Trippa F, Maranzano E, Carosi A, Ponti E, Arcidiacono F, et al. Stereotactic body radiotherapy in oligometastatic prostate cancer patients with isolated lymph nodes involvement: a two-institution experience. World J Urol. 2017;35(1):45-9.

72. Koerber SA, Katharina S, Clemens K, Erik W, Matthias FH, Sonja K, et al. Clinical outcome of PSMA-guided radiotherapy for patients with oligorecurrent prostate cancer. Eur J Nucl Med Mol Imaging. 2020;48(1):143-51.

73. James ND, Sydes MR, Clarke NW, Mason MD, Dearnaley DP, Spears MR, et al. Addition of docetaxel, zoledronic acid, or both to first-line long-term hormone therapy in prostate cancer (STAMPEDE): survival results from an adaptive, multiarm, multistage, platform randomised controlled trial. Lancet (Lond, Engl). 2016;387(10024):1163-77.
74. Sweeney CJ, Chen YH, Carducci M, Liu G, Jarrard DF, Eisenberger M, et al. Chemohormonal therapy in metastatic hormone-sensitive prostate cancer. N Engl J Med. 2015;373(8):737-46.

75. Napieralska A, Miszczyk L, Stąpór-Fudzińska M. CyberKnife stereotactic ablative radiotherapy as an option of treatment for patients with prostate cancer having oligometastatic lymph nodes: single-center study outcome evaluation. Technol Cancer Res Treat. 2016:15(5):661-73.

76. Tran S, Jorcano S, Falco T, Lamanna G, Miralbell R, Zilli T. Oligorecurrent nodal prostate cancer. Am J Clin Oncol Cancer Clin Trials. 2018;41(10):960-2.

77. Mazzola R, Francolini G, Triggiani L, Napoli G, Cuccia F, Nicosia L, et al. Metastasis-directed therapy (SBRT) guided by PET-CT (18)F-CHOLINE versus PET-CT (68)Ga-PSMA in castration-sensitive oligorecurrent prostate cancer: a comparative analysis of effectiveness. Clin Genitourin Cancer. 2020;S1558-7673(20)30191-9.

78. Clement JM, Sweeney CJ. Evolving treatment of oligometastatic hormone-sensitive prostate cancer. J Oncol Pract. 2017;13(1):9-18.

79. Foster CC, Weichselbaum RR, Pitroda SP. Oligometastatic prostate cancer : reality or figment of imagination? Cancer. 2019;125(3):340-52.

80. Kothari G, Ost P, Cheung P, Blanchard P, Tree AC, van As NJ, et al. Trends in management of oligometastatic hormone-sensitive prostate cancer. Curr Oncol Rep. 2019;21(5):43.

81. Palacios-eito OA, Palacios-eito A, Béjar-luque A, Rodríguez-liñán M, García-cabezas S. Oligometastases in prostate cancer: ablative treatment. World J Clin Oncol. 2019;10(2):38-52.

82. Jereczek-Fossa BA, Beltramo G, Fariselli L, Fodor C, Santoro L, Vavassori $A$, et al. Robotic image-guided stereotactic radiotherapy, for isolated recurrent primary, lymph node or metastatic prostate cancer. Int J Radiat Oncol Biol Phys. 2012;82(2):889-97.

83. Detti B, Bonomo P, Masi L, Doro R, Cipressi S, lermano C, et al. Stereotactic radiotherapy for isolated nodal recurrence of prostate cancer. World J Urol. 2015;33(8):1197-203.

84. Steuber T, Jilg C, Tennstedt P, De Bruycker A, Tilki D, Decaestecker K, et al. Standard of care versus metastases-directed therapy for PET-detected nodal oligorecurrent prostate cancer following multimodality treatment: a multi-institutional case-control study. Eur Urol Focus. 2019;5(6):1007-13.

85. Loi M, Di Cataldo V, Francolini G, Bonomo P, Masi L, Simontacchi G, et al. Single-fraction stereotactic body radiotherapy for oligometastatic lymph node relapse in prostate cancer. Oncol Res Treat. 2018;41(11):703-5.

\section{Publisher's note}

Springer Nature remains neutral with regard to jurisdictional claims in published maps and institutional affiliations.
Ready to submit your research? Choose BMC and benefit from:

- fast, convenient online submission

- thorough peer review by experienced researchers in your field

- rapid publication on acceptance

- support for research data, including large and complex data types

- gold Open Access which fosters wider collaboration and increased citations

- maximum visibility for your research: over $100 \mathrm{M}$ website views per year

At BMC, research is always in progress.

Learn more biomedcentral.com/submissions 